\title{
Influence of Friction Factor and Flow Equation on Calculation of Gas- Distribution Pipeline Networks
}

\author{
Dejan BRKIĆ \\ Ministry of Science and Technological Development, Beograd, Serbia. \\ dejanrgf@tesla.rcub.bg.ac.rs, dejanbrkic0611@gmail.com
}

\begin{abstract}
C Here is shown method for the hydraulic solution of a looped gas-pipeline networks. Calculation of presented network is done according to principles of Hardy Cross method. The optimization was carried out by iteration of the pipes diameters, node consumptions are known and flow velocities through pipes have to stand below certain values. Accent is on determination of appropriate friction factor, and on selection of representative equation for natural gas flow under presented conditions in the network. Inappropriate usage of friction factor, equally as inappropriate usage of gas flow equation can lead to inaccurate final results. Here is shown new facts in comparison to previous calculation of gas distribution network in Kragujevac, Serbia which is done in 1994. After the implementation, measurements in situ have performed, and real measured values deviate from calculated. Causes for these errors are investigated, and improved and more accurate procedure is shown.
\end{abstract}

Keywords-- natural gas; distribution; pipeline network; friction; hydraulics resistance.

\section{INTRODUCTION}

When a gas is forced to flow through pipes it expands to a lower pressure and changes its density. Flow-rate equations for condition in gas distribution networks assume a constant density of a fluid within the pipes. This assumption applies only to incompressible flows. This kind of flow regime is most suitable for waterdistribution systems for municipalities (or any other liquid, like oil, etc.). For the condition of pressure drop in typical gas distribution networks, gas can be treated as incompressible fluid, i.e. liquid. But even under these circumstances flow equation for water or crude oil cannot be literally copied and applied for natural gas flow. Gas consumption has grown rapidly nowadays in the world, and as a result new equations for flow and pressure drops in the distribution networks are developed and established in engineering practice. This paper addresses to the problem of hydraulic resistance in pipes used for construction of networks for distribution of natural gas in the cities and with subject to all the practical requirements for the engineers charged with design and/or analysis of such system. This paper is especially addressed to those engineers willing to understand and interpret the results of calculation properly and to make good engineering decision based on this subject.
Every pipe is connected to two nodes at its ends. In a pipe network system, pipes are the channels used to convey fluid from one location to another. The physical characteristics of a pipe include the length, inside diameter, roughness coefficient, and minor loss coefficient. The pipe roughness coefficient is associated with the pipe material and age. The minor loss coefficient is due to the fittings along the pipe. When fluid is conveyed through the pipe, hydraulic energy is lost due to the friction between the moving fluid and the stationary pipe surface. This friction loss is a major energy loss in pipe flow and is a function of flow rate, pipe length, diameter, and roughness coefficient. In the paper of Manojlović et al. (1994), which deals with optimized design of a gas-distribution pipeline network in the town of Kragujevac in Serbia, the Darcy-Weisbach formula with incorporated friction factor developed by Schifrison is applied. In the present practice, Renouard (1962) equation is used by the engineers from Serbia and other countries, such as France, Spain, Portugal, etc. Advantage of this or similar equations are to be explained in further discussion. Previous calculation of the gas network of Kragujevac from 1994. is very similar with calculation of water distribution networks (Sorbu and Borza, 1997; Samani and Naeeni, 1996; Kim, 2007), and according to this fact some deviations are occurred in real conditions apropos calculated results.

This paper is referring to work of Hardy Cross (1936) in the field of analysis of flows in networks, with improvement of method by Epp and Fowler (1970) which is also based on in loop-oriented equations (modified Hardy Cross method). The Newton-Raphson method is used by Epp and Fowler (1970) to linearize the nonlinear mass and energy equations and to solve set of equations simultaneously while the approach of Hardy Cross is to solve these equations successively. Finale result (same results for both methods, but after different number of iterations) is to be done after iterative procedure according to above cited methods. This paper deal also with turbulent flow in a smooth and in a rough pipes, with friction factors and flow regimes investigated by Reynolds (1883), Blasius (1908; Roberson and Crowe, 1985), Nikuradze (1933), Moody (1944, 1947), Colebrook (1939), Colebrook and White (1937), Altshul (1982; Nekrasov 1969), Shifrinson (1937), Renouard (1962) and others. 


\section{METHODS AND MAIN TEXT}

A. Comments on previously adopted friction factor and used equations

Losses of energy, or head (pressure) losses depend on the shape, size and roughness of a channel, the velocity and viscosity of a fluid, and they do not depend on the absolute pressure of the fluid. Experiments show that in many cases pressure drop are approximately proportional to the square of the velocity (eq. 1).

$$
\mathrm{p}_{2}-\mathrm{p}_{1}=0.5 \cdot \lambda \cdot \mathrm{L} \cdot \mathrm{v}^{2} \cdot \rho \cdot \mathrm{D}_{\text {in }}^{-1},
$$

Equation (1) is called the Darcy-Weisbach (1857) equation, named after Henry Darcy, a French engineer of the nineteenth century, and Julius Weisbach, a German engineer and the scientist of the same era. Weisbach first proposed the use of non-dimensional resistance coefficient $^{1}$, and Darcy carried out numerous tests on water pipes. Further, velocity can be replaced by flow (eq. 2):

$$
\mathrm{p}_{2}-\mathrm{p}_{1}=8 \cdot \lambda \cdot \mathrm{L} \cdot \mathrm{Q}^{2} \cdot \rho \cdot \mathrm{D}_{\mathrm{in}}^{-5} \cdot \pi^{-2}=\mathrm{S}_{1} \cdot \mathrm{Q}^{2},
$$

Further, to predict whether flow will be laminar or turbulent, it is necessary to explore the characteristics of flow in both laminar and turbulent states. O. Reynolds found that the onset of turbulence in pipe was related to one non-dimensional parameter (eq. 3$)^{2}$ :

$$
\operatorname{Re}=\mathrm{v} \cdot \mathrm{D}_{\text {in }} \cdot \rho \cdot \eta^{-1}=\mathrm{v} \cdot \mathrm{D}_{\text {in }} \cdot \mu^{-1}
$$

Flow regime will be changed from laminar to turbulent at a Reynolds number in the neighborhood of 2100 (or higher under special circumstances). For laminar flow (see line A in fig. 1 and 2), resistance coefficient is given by eq. 4 (Hagen-Poiseuille equation):

$$
\lambda=64 \cdot \mathrm{Re}^{-1},
$$

Further, for turbulent flow, in smooth pipes friction losses are completely determined by Reynolds number (see line B in fig. 1 and 2). In rough pipes, however, the value of friction coefficient depends also on the roughness of the inside pipe surface. The important point is not so much the absolute roughness size-k of the projections as the so-called relative roughness-k/D; for the same absolute roughness may have no effect on the resistance of a large pipe and considerably increase the resistance of a small one. So, the friction coefficient depends both on $\mathrm{Re}$ and on the ratio-k/D: $\lambda=f(R e ; k / D)$. Simultaneous effect of these two parameters on pipe friction is shown in the fig. 1 (zone 2), based on experiments of Nikuradse (1933) and Moody (1944). Zone 1 in fig. 1 is the area of unstable flow and should to be

\footnotetext{
${ }^{1}$ In USA coefficient after Fanning $-\mathrm{f}$ is common $(\lambda=4 \mathrm{f})$

${ }^{2}$ Assuming a gas dynamic viscosity of $1.0758 \cdot 10^{-5}$ Pas typical of natural gases: $\mathrm{Re}=145158.7 \cdot \mathrm{Q}_{0} \cdot \rho \cdot \mathrm{D}^{-1}$ (density natural of natural gas calculated from available date from the paper of Manojlović et al. (1994) is $1.09 \mathrm{~kg} \cdot \mathrm{m}^{-3}$ (relative density 0,84 while for natural gas in Serbian this parameter are taken with $0.64)$
}

avoid in technical systems. In zone 3 (fig. 1) friction coefficient depends only on relative roughness; $\lambda=\mathrm{f}(\mathrm{k} / \mathrm{D})$.

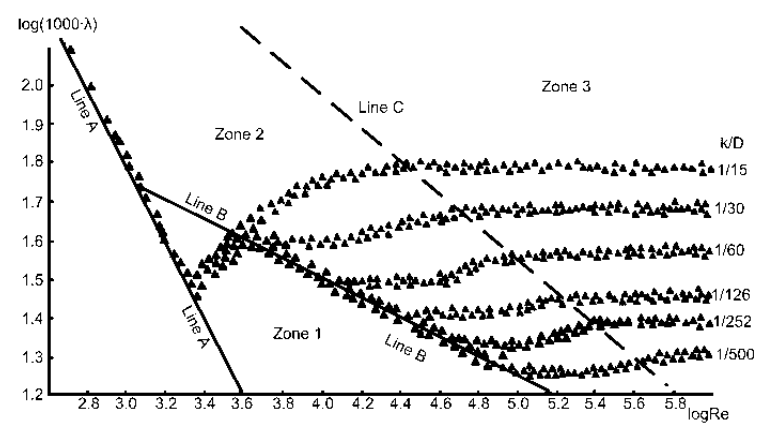

Figure 1. Friction factor $(\lambda)$ versus Reynolds number for sand-roughened pipes

The inclined straight lines A and B (fig 1 and 2) correspond to the resistance laws for smooth pipes, i.e. eq. 4 $\left(\right.$ line A) ${ }^{3}$ and eq. 5 (line B) ${ }^{4}$, which multiplied by 1000 and the logarithm taken, give linear function for the given coordinate system in fig 1. Churchil (1977) tried to develop equation for all regimes.

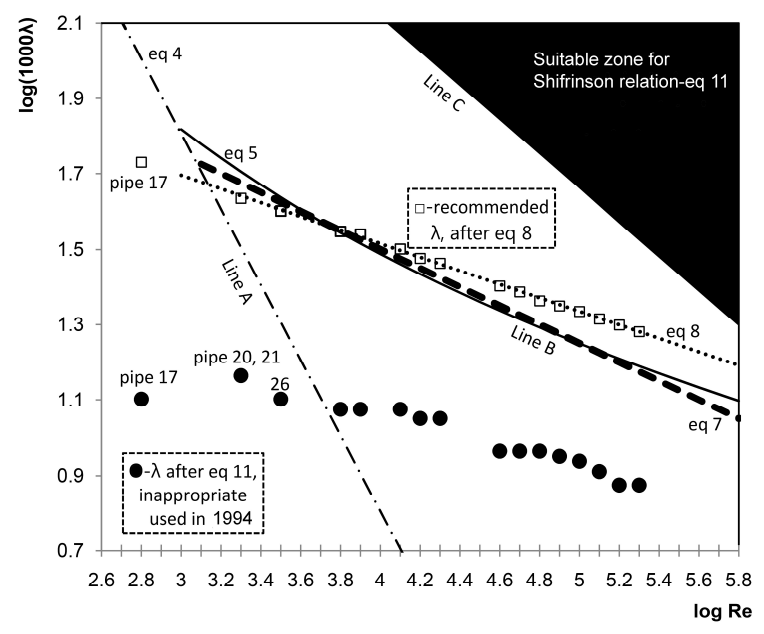

Figure 2. Identification of the problem in a characteristic diagram (shown in Fig 1)

$$
\lambda=0.3164 \cdot \mathrm{Re}^{-1 / 4},
$$

The lines defined by triangles in fig 1 . are curves plotted for pipes with different relative roughness. The following conclusions can be drawn from the fig 1 :

1. In laminar flow roughness does not affect resistance; the broken curves corresponding to various degrees practically coincide with line A in fig 1 and 2 (eq. 4).

2. The critical Reynolds number practically does not depend on roughness. The triangle curves (see eq. 6) (Obrović and Šašić, 1990) in fig. 1 diverge from line A

\footnotetext{
${ }^{3} \log (1000 \cdot \lambda)=\log 64000-\log R e$

${ }^{4} \log (1000 \cdot \lambda)=\log 316.4-0.25 \cdot \log \operatorname{Re}$
} 
at about same value of Re (unstable regime; transition region; zone 1 in fig 1 ):

$$
\lambda=0.0025 \cdot \sqrt[3]{\operatorname{Re}}
$$

3. In turbulent flow when Re and $\mathrm{k} / \mathrm{D}$ are small roughness does not affect resistance; in some places the triangle lines coincide with line B in fig 1 and 2 (eq. 5). Similar results are brought by Konakov (eq. 7; available from (Obrović and Sašić, 1990)) and Renouard (1962) relation; eq 8:

$$
\begin{aligned}
& \lambda=0.0025 \cdot \sqrt[3]{\mathrm{Re}}, \\
& \lambda=0.172 \cdot \mathrm{Re}^{-0.18},
\end{aligned}
$$

4. However, with Re increasing the roughness begins to take effect and the curves for rough pipes begin to deviate from the straight line of resistance law for smooth pipes (zone 2 in fig 1). Relations of Altshul (1982) (eq 9) and Colebrook (1939; Colebrook and White, 1937; Swamee and Jain, 1976) (eq 10) are valuable for this partially turbulent zone:

$$
\begin{aligned}
\lambda= & 0.1 \cdot\left(\frac{1.46 \cdot \mathrm{k}}{\mathrm{D}_{\text {in }}}+\frac{100}{\mathrm{Re}}\right)^{\frac{1}{4}}=0.11 \cdot\left(\frac{\mathrm{k}}{\mathrm{D}_{\text {in }}}+\frac{68}{\mathrm{Re}}\right)^{\frac{1}{4}}, \\
& \frac{1}{\sqrt{\lambda}}=-2 \cdot \log \left(\frac{2.51 \cdot \mathrm{k}}{\mathrm{Re} \cdot \sqrt{\lambda}}+\frac{\mathrm{k}}{3.71 \cdot \mathrm{D}_{\text {in }}}\right) \Rightarrow \\
& \Rightarrow \lambda=\frac{0.25}{\left[\log \left(\frac{\mathrm{k}}{3.7 \cdot \mathrm{D}_{\text {in }}}=\frac{5.74}{\mathrm{Re}^{0.9}}\right)\right]},
\end{aligned}
$$

5. At high values of $\mathrm{Re}$ and $\mathrm{K} / \mathrm{D}$ the friction factor no longer depends on Reynolds number and becomes constant for a given relative roughness. This corresponds to the horizontal portions of the triangle lines (zone 3 in fig 1 and zone marked with black colour in fig 2). Relations of Shifrinson (1937) (eq 11) or special Colebrook (1939; Colebrook and White, 1937; Swamee and Jain, 1976) (in explicit form) can be applied for this, fully turbulent regime (eq 12):

$$
\begin{gathered}
\lambda=0.11 \cdot\left(\mathrm{k} / \mathrm{D}_{\text {in }}\right)^{1 / 4}, \\
\lambda=0.25 \cdot \log \left(3.71 \cdot \mathrm{D}_{\text {in }} \cdot \mathrm{k}^{-1}\right)^{-2},
\end{gathered}
$$

Explicit equations were developed by Chen (1979), Round (1980), Romeo et al. (2002) and others.

According to main project of gas pipeline of Kragujevac (results are presented also in paper by Manojlović et al. (1994), friction coefficient in pipes (network in fig. 2) is calculated after Shifrinson (1937) equation (eq. 11). Pipe roughness is reported as $\mathrm{k}=0.007 \mathrm{~mm}$ (Manojlović et al., 1994). In fig. 1, minimal relative roughness $\mathrm{k} / \mathrm{D}$ is $1 / 500=0.002$, while in the paper of Manojlović et al., (1994) are in range from 0.000032 to 0.000455 ( $\log \mathrm{Re}$ is in range from 2.8 to 5.3). So,
Shifrinson (1937) equation (eq. 11) cannot be used, here can be recommended some of the relations correlated to line B in fig 1 and 2. These equations are (5), (7) and (8).Especially, Renouard (1962) equations are frequently used in Serbia, France, Portugal (Coelho and Pinho, 2007), Spain and many other countries for the sizing of distribution gas lines. Today, polyethylene pipes (von Bernuth and Wilson) are used for construction of gas distribution networks, and these pipes are approximately smooth. Also in pipe 17, flow is practically laminar (fig 2 and 3), and Shifrinson relation (1937) is for extremely turbulent conditions. Application of Shifrinson equation (1937) in the calculation of Kragujevac's network implies that pipes 17, 20, 21 and 26 are belong to nonexistent sub-laminar zone (below laminar) and all other remain pipes belong to highly unstable zone 1 , between line $A$ and $B$ in fig. 1 and 2. Pipe 17 is already very thin $(27.4 \mathrm{~mm})$ but with laminar flow, and it is potential candidate for troubles in exploitation of the network. Detail report for inner roughness for different types of pipes can be found in Oil and Gas Journal, 03.05.1965.

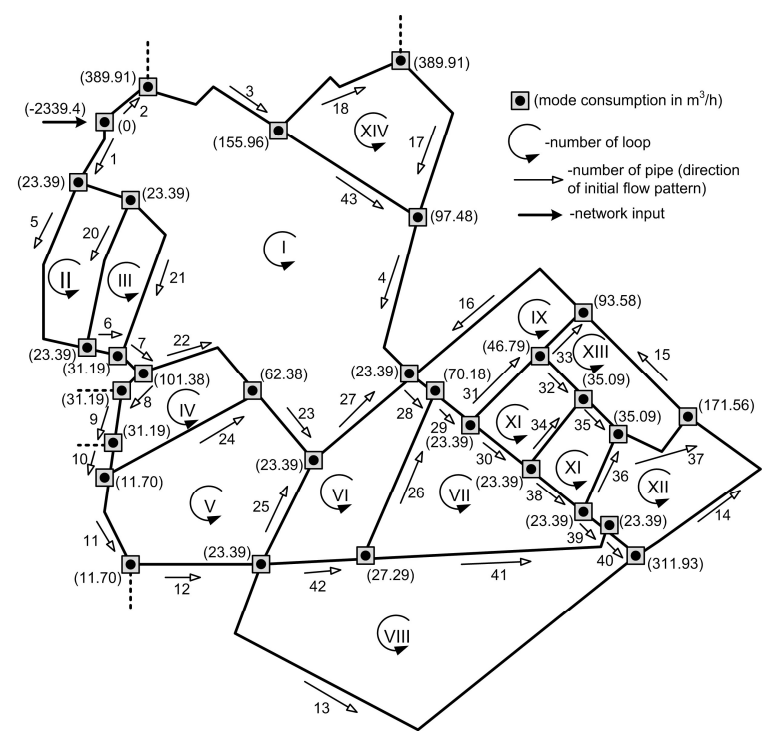

Figure 3. Gas-pipeline network in Kragujevac

For the gas flow in horizontal pipes with constant diameter, eq. 1. can be arranged as eq. (13):

$$
\int_{p_{1}}^{\mathrm{p}_{2}} \frac{\mathrm{dp}}{\rho \cdot \mathrm{g}}+\int_{1}^{2} \frac{2 \cdot \lambda \cdot \rho \cdot \mathrm{v}^{2}}{2 \cdot \mathrm{D}_{\mathrm{in}}} \mathrm{dL}=0
$$

Where are:

$$
\begin{gathered}
\mathrm{Q}=\frac{\mathrm{Q}_{0} \cdot \mathrm{T} \cdot \mathrm{z}}{\mathrm{T}_{0} \cdot \mathrm{z}_{0}}, \\
\mathrm{v}=\frac{4 \cdot \mathrm{Q}_{0} \cdot \mathrm{p}_{0} \cdot \mathrm{T} \cdot \mathrm{z}}{\mathrm{D}_{\text {in }}^{2} \cdot \pi \cdot \mathrm{p} \cdot \mathrm{T}_{0} \cdot \mathrm{z}_{0}}, \\
\rho=\frac{\mathrm{p} \cdot \rho_{\mathrm{r}}}{\mathrm{z} \cdot \mathrm{R} \cdot \mathrm{T}},
\end{gathered}
$$


Equation 13 with replacements shown above (eq 14, 15 and 16) and after integration becomes eq. (17):

$$
\mathrm{p}_{2}^{2}-\mathrm{p}_{1}^{2}=\frac{16 \cdot \mathrm{Q}_{0}^{2} \cdot \lambda \cdot \mathrm{T}^{2} \cdot \mathrm{p}_{0}^{2} \cdot \mathrm{z} \cdot \mathrm{L}}{\mathrm{R} \cdot \mathrm{T} \cdot \pi^{2} \cdot \mathrm{T}_{0}^{2} \cdot \mathrm{D}_{\mathrm{in}}^{5} \cdot \mathrm{Z}_{0}^{2}}
$$

Now, friction factor- $\lambda$, can be replaced with Renouard relation (8), and after transformation - see details in the papers of Renouard (1962) and Coelho and Pinho (2007), final equation can be written as (18):

$$
\mathrm{p}_{2}^{2}-\mathrm{p}_{1}^{2}=4810 \cdot \frac{\rho_{\mathrm{r}} \cdot \mathrm{L} \cdot \mathrm{Q}_{0}^{1.82}}{\mathrm{D}_{\mathrm{in}}^{4.82}}=\mathrm{S}_{2} \cdot \mathrm{Q}_{0}^{1.82}
$$

This last equation is only valid in the cases when $\mathrm{Q}$ $[\mathrm{m} 3 / \mathrm{h}] / \mathrm{D}[\mathrm{mm}]<150$ (in our case that value is $\max 6$ ), i.e. this means that $\operatorname{Re}<4 \cdot 10^{6}$ (in our case max Re is estimated as $2.003226 \cdot 10^{5}$ ). Here have to be notified that in the development Renouard equation, a constant value for city gas kinematic had been used for viscosity, i.e. $\mu=2.2 \cdot 10^{-5} \mathrm{~m}^{2} / \mathrm{s}$, and a flow temperature of $15^{\circ} \mathrm{C}$. This means that by fixing the value of gas cinematic viscosity, the density is also kept fixed, which is physically inaccurate when considering compressible gas flows at medium or high pressure, because the cinematic viscosity of gases is highly dependent upon pressure.

\section{B. Comparison of the actual and previous results}

In fig 3 is shown ring-like part of the gas distribution network from the one of the urban zone from the town of Kragujevac in Serbia (Manojlović et al., 1994). There are 29 independent nodes in the ring-like network, 43 branches belonging to rings with 25 branches mutual to the two rings. Gas consumption per node is represented in fig 3 and computation results with new equation with new friction factor incorporated in are compared with in results presented in (Manojlović et al., 1994) are shown in Table 1 . The velocity limits are $6 \mathrm{~m} / \mathrm{s}$ for the pipes of small diameter (up to $90 \mathrm{~mm}$ ) and $12 \mathrm{~m} / \mathrm{s}$ for the pipes of large diameter (up to $225 \mathrm{~mm}$ ). The total network gas supply input in node 1 is $2339.4 \mathrm{~m}^{3} / \mathrm{h}$. Calculation is done according to original Hardy Cross (1936) method, improved Hardy Cross method, both with Schifrinson (1937) and Renoard (1962) friction factor (Coelho and Pinho, 2007). Relation for corrections used in Hardy Cross method (19) is done based on relation (2) showed also in the paper of Manojlović et al., (1994), and here presented relation (18).

$$
\begin{gathered}
\Delta_{j}=-\frac{F\left(Q_{i}\right)_{j}^{(m-1)}}{\left.\frac{\partial F\left(Q_{i}\right)_{j}}{\partial\left(\Delta Q_{j}\right)}\right|_{Q^{(m-1)}} ^{(m)}}= \\
=-\frac{\left(\sum S_{i} \cdot Q_{i}^{n}\right)_{j}^{(m-1)}}{\left(n \cdot \sum\left|S_{i} \cdot Q_{i}^{n-1}\right|\right)_{j}^{(m-1)}}
\end{gathered}
$$

This relation (19) becomes with of implementation of eq 2 and eq 11 used in previous calculation from 1994 (eq. 20):

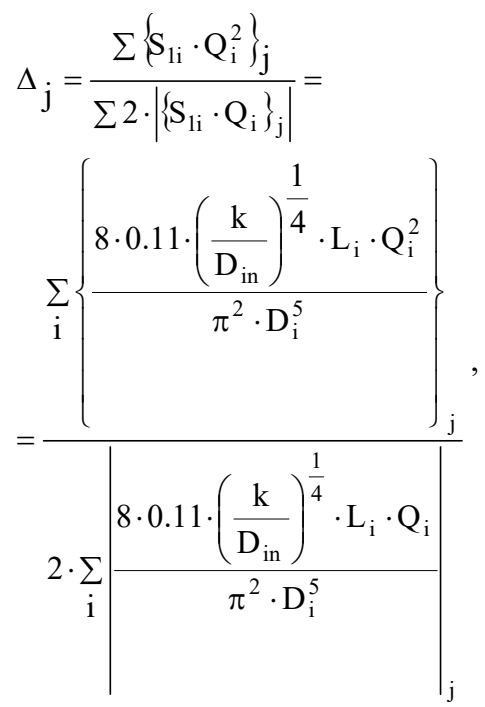

Also eq 19 after implementation of eq 18, becomes (eq. 21):

$$
\begin{gathered}
\Delta_{j}=\frac{\sum\left\{\mathrm{S}_{2 \mathrm{i}} \cdot \mathrm{Q}_{\mathrm{i}}^{1.82}\right\}_{\mathrm{j}}}{\sum 2 \cdot\left|\left\{\mathrm{S}_{2 \mathrm{i}} \cdot \mathrm{Q}_{\mathrm{i}}^{1.82-1}\right\}_{\mathrm{j}}\right|}= \\
=\frac{\sum_{\mathrm{i}}\left\{\frac{4810 \cdot \rho_{\mathrm{r}} \cdot \mathrm{L}_{\mathrm{i}} \cdot \mathrm{Q}_{\mathrm{i}}^{1.82}}{\pi^{2} \cdot \mathrm{D}_{\mathrm{i}}^{5}}\right\}_{\mathrm{j}}}{1.82 \cdot \sum_{\mathrm{i}}\left|\frac{4810 \cdot \rho_{\mathrm{r}} \cdot \mathrm{L}_{\mathrm{i}} \cdot \mathrm{Q}_{\mathrm{i}}^{0.82}}{\pi^{2} \cdot \mathrm{D}_{\mathrm{i}}^{5}}\right|_{j}},
\end{gathered}
$$

Above showed relations are used for calculation after original Hardy Cross (1936) method (successive calculation), and relations for improvement method is complicated in a mathematic approach (Newton-Raphson simultaneous solution), but not in basic assumption. This improvement cause increase speed of converging in iterative procedure without affect on final result. As a consequence, conclusion is that results are not depend on chosen method (original vs. improved Hardy Cross). 
Table 1. Comparisons of computational results (hydraulics resistances and pressures drops)

\begin{tabular}{|c|c|c|c|c|c|c|c|c|}
\hline \multicolumn{3}{|c|}{ Pipe } & \multirow{3}{*}{$\begin{array}{c}\text { Reynolds } \\
\text { number } \\
\text { Re }\end{array}$} & \multicolumn{2}{|c|}{ Hydraulics resistance } & \multicolumn{3}{|c|}{ Pressure drop $(\mathrm{Pa})$} \\
\hline & \multirow{2}{*}{$\begin{array}{c}\mathrm{D}(\mathrm{m} \\
\mathrm{m})\end{array}$} & \multirow[t]{2}{*}{$\mathrm{L}(\mathrm{m})$} & & \multirow{2}{*}{$\begin{array}{c}\mathrm{S}_{1} * \\
\text { eq }(2)\end{array}$} & \multirow{2}{*}{$\begin{array}{c}\mathrm{S}_{2} \\
\text { eq }(18)\end{array}$} & $\begin{array}{l}{ }^{\text {a After } *} \\
\text { eq }(20)\end{array}$ & $\begin{array}{c}{ }^{\mathrm{b}} \mathrm{I} \\
\mathrm{eq}(20)\end{array}$ & $\begin{array}{c}\text { cII } \\
\text { eq }(21)\end{array}$ \\
\hline & & & & & & with $\mathrm{S}_{1}$ & & with $\mathrm{S}_{2}$ \\
\hline 1 & 220.4 & 84 & $1.59 \cdot 10^{5}$ & $1.071 \cdot 10^{3}$ & $4.97 \cdot 10^{8}$ & 93.54 & 89.29 & 7176 \\
\hline 2 & 220.4 & 72 & $2.00 \cdot 10^{5}$ & $9.183 \cdot 10^{2}$ & $4.26 \cdot 10^{8}$ & 115.30 & 119.75 & 8190 \\
\hline 3 & 198.2 & 170 & $1.56 \cdot 10^{5}$ & $3.786 \cdot 10^{3}$ & $1.68 \cdot 10^{9}$ & 229.18 & 241.98 & 11762 \\
\hline 4 & 109.8 & 206 & $8.34 \cdot 10^{4}$ & $1.019 \cdot 10^{5}$ & $3.50 \cdot 10^{10}$ & 464.04 & 559.74 & 17742 \\
\hline 5 & 198.2 & 224 & $1.69 \cdot 10^{5}$ & $4.988 \cdot 10^{3}$ & $2.21 \cdot 10^{9}$ & 396.32 & 377.57 & 14486 \\
\hline 6 & 198.2 & 37 & $1.65 \cdot 10^{5}$ & $8.239 \cdot 10^{2}$ & $3.65 \cdot 10^{8}$ & 62.59 & 59.58 & 5767 \\
\hline 7 & 198.2 & 30 & $1.60 \cdot 10^{5}$ & $6.681 \cdot 10^{2}$ & $2.96 \cdot 10^{8}$ & 47.75 & 45.35 & 5044 \\
\hline 8 & 176.2 & 35 & $1.05 \cdot 10^{5}$ & $1.446 \cdot 10^{3}$ & $6.09 \cdot 10^{8}$ & 35.87 & 33.83 & 4423 \\
\hline 9 & 176.2 & 64 & $9.86 \cdot 10^{4}$ & $2.643 \cdot 10^{3}$ & $1.11 \cdot 10^{9}$ & 58.57 & 55.06 & 5668 \\
\hline 10 & 158.6 & 34 & $1.03 \cdot 10^{5}$ & $2.440 \cdot 10^{3}$ & $9.83 \cdot 10^{8}$ & 47.95 & 44.91 & 5028 \\
\hline 11 & 158.6 & 119 & $9.28 \cdot 10^{4}$ & $8.540 \cdot 10^{3}$ & $3.44 \cdot 10^{9}$ & 136.07 & 127.38 & 8562 \\
\hline 12 & 158.6 & 154 & $9.03 \cdot 10^{4}$ & $1.105 \cdot 10^{4}$ & $4.45 \cdot 10^{9}$ & 167.14 & 156.19 & 9501 \\
\hline 13 & 44.0 & 639 & $1.65 \cdot 10^{4}$ & $3.845 \cdot 10^{7}$ & $8.92 \cdot 10^{12}$ & 1658.30 & 1450.32 & 28159 \\
\hline 14 & 35.2 & 268 & $6.60 \cdot 10^{3}$ & $5.203 \cdot 10^{7}$ & $1.10 \cdot 10^{13}$ & 504.30 & 205.66 & 11081 \\
\hline 15 & 35.2 & 164 & $7.24 \cdot 10^{3}$ & $3.184 \cdot 10^{7}$ & $6.71 \cdot 10^{12}$ & 337.89 & 119.42 & 9437 \\
\hline 16 & 44.0 & 276 & $1.95 \cdot 10^{4}$ & $1.661 \cdot 10^{7}$ & $3.85 \cdot 10^{12}$ & 962.57 & 854.72 & 21596 \\
\hline 17 & 27.4 & 363 & $6.44 \cdot 10^{2}$ & $2.625 \cdot 10^{8}$ & $4.97 \cdot 10^{13}$ & 66.27 & 2.17 & 2261 \\
\hline 18 & 123.4 & 175 & $1.07 \cdot 10^{5}$ & $4.689 \cdot 10^{4}$ & $1.70 \cdot 10^{10}$ & 545.01 & 549.19 & 17248 \\
\hline 19 & 44.0 & 52 & $1.95 \cdot 10^{4}$ & $3.129 \cdot 10^{6}$ & $7.26 \cdot 10^{11}$ & 158.87 & 157.02 & 9394 \\
\hline 20 & 15.4 & 177 & $2.11 \cdot 10^{3}$ & $2.636 \cdot 10^{9}$ & $3.90 \cdot 10^{14}$ & 156.13 & 220.56 & 14473 \\
\hline 21 & 15.4 & 212 & $2.18 \cdot 10^{3}$ & $3.157 \cdot 10^{9}$ & $4.67 \cdot 10^{14}$ & 465.91 & 280.14 & 9427 \\
\hline 22 & 109.8 & 161 & $8.91 \cdot 10^{4}$ & $7.964 \cdot 10^{4}$ & $2.74 \cdot 10^{10}$ & 531.01 & 502.05 & 16666 \\
\hline 23 & 123.4 & 108 & $7.20 \cdot 10^{4}$ & $2.894 \cdot 10^{4}$ & $1.05 \cdot 10^{10}$ & 162.96 & 151.49 & 9431 \\
\hline 24 & 55.4 & 194 & $2.18 \cdot 10^{4}$ & $3.482 \cdot 10^{6}$ & $8.92 \cdot 10^{11}$ & 399.83 & 368.24 & 14170 \\
\hline 25 & 96.8 & 135 & $5.17 \cdot 10^{4}$ & $1.294 \cdot 10^{5}$ & $4.22 \cdot 10^{10}$ & 228.49 & 236.17 & 11232 \\
\hline 26 & 27.4 & 215 & $3.32 \cdot 10^{3}$ & $1.555 \cdot 10^{8}$ & $2.94 \cdot 10^{13}$ & 74.44 & 104.18 & 7739 \\
\hline 27 & 141.0 & 155 & $9.29 \cdot 10^{4}$ & $2.063 \cdot 10^{4}$ & $7.90 \cdot 10^{9}$ & 252.12 & 243.14 & 11665 \\
\hline 28 & 158.6 & 34 & $1.30 \cdot 10^{5}$ & $2.440 \cdot 10^{3}$ & $9.83 \cdot 10^{8}$ & 65.45 & 69.70 & 6214 \\
\hline 29 & 158.6 & 48 & $1.15 \cdot 10^{5}$ & $1.112 \cdot 10^{4}$ & $4.48 \cdot 10^{9}$ & 72.40 & 251.40 & 11921 \\
\hline 30 & 123.4 & 86 & $1.03 \cdot 10^{5}$ & $2.305 \cdot 10^{4}$ & $8.33 \cdot 10^{9}$ & 222.90 & 254.36 & 11701 \\
\hline 31 & 96.8 & 115 & $4.92 \cdot 10^{4}$ & $1.102 \cdot 10^{5}$ & $3.59 \cdot 10^{10}$ & 177.56 & 165.81 & 9906 \\
\hline 32 & 35.2 & 75 & $1.73 \cdot 10^{4}$ & $1.456 \cdot 10^{7}$ & $3.07 \cdot 10^{12}$ & 440.09 & 368.21 & 14126 \\
\hline 33 & 55.4 & 70 & $4.63 \cdot 10^{4}$ & $1.257 \cdot 10^{6}$ & $3.22 \cdot 10^{11}$ & 588.30 & 541.36 & 16901 \\
\hline 34 & 96.8 & 102 & $6.89 \cdot 10^{4}$ & $9.778 \cdot 10^{4}$ & $3.18 \cdot 10^{10}$ & 256.26 & 291.81 & 12679 \\
\hline 35 & 96.8 & 52 & $6.29 \cdot 10^{4}$ & $4.985 \cdot 10^{4}$ & $1.62 \cdot 10^{10}$ & 109.85 & 124.18 & 8335 \\
\hline 36 & 35.2 & 104 & $1.20 \cdot 10^{4}$ & $2.019 \cdot 10^{7}$ & $4.26 \cdot 10^{12}$ & 337.54 & 256.88 & 11881 \\
\hline 37 & 96.8 & 101 & $5.50 \cdot 10^{4}$ & $9.682 \cdot 10^{4}$ & $3.15 \cdot 10^{10}$ & 165.02 & 185.16 & 10278 \\
\hline 38 & 96.8 & 86 & $5.47 \cdot 10^{4}$ & $8.244 \cdot 10^{4}$ & $2.69 \cdot 10^{10}$ & 136.26 & 159.11 & 9438 \\
\hline 39 & 96.8 & 37 & $4.22 \cdot 10^{4}$ & $3.547 \cdot 10^{4}$ & $1.16 \cdot 10^{10}$ & 32.07 & 40.68 & 4885 \\
\hline 40 & 96.8 & 30 & $1.04 \cdot 10^{5}$ & $2.876 \cdot 10^{4}$ & $9.37 \cdot 10^{9}$ & 199.03 & 195.71 & 10007 \\
\hline 41 & 96.8 & 278 & $7.01 \cdot 10^{4}$ & $2.665 \cdot 10^{5}$ & $8.68 \cdot 10^{10}$ & 947.34 & 809.77 & 21257 \\
\hline 42 & 96.8 & 115 & $8.06 \cdot 10^{4}$ & $1.102 \cdot 10^{5}$ & $3.59 \cdot 10^{10}$ & 508.19 & 444.84 & 15522 \\
\hline 43 & 123.4 & 199 & $1.01 \cdot 10^{5}$ & $5.333 \cdot 10^{4}$ & $1.93 \cdot 10^{10}$ & 480.40 & 547.02 & 17395 \\
\hline
\end{tabular}

*Previous results from 1994.; Results II are recommended; 464052>S2/S1>147925

aafter unknown number of iterations in the paper of Manojlović et al., (1994) (here after 2 iterations in improved method, and after 146 in original method), bafter 9 iterations in improved method, and after approx. 1500 iterations in original method; ' after 12 iterations in improved method, and after approx. 1150 iterations in original method

Table 2. Comparisons of computational results (flows) 


\begin{tabular}{|c|c|c|c|c|c|}
\hline \multirow[b]{2}{*}{$\begin{array}{l}\text { Branch } \\
\text { number }\end{array}$} & \multicolumn{4}{|c|}{ aFlows: $\left(\mathrm{m}^{3} / \mathrm{h}\right)$} & \multirow{2}{*}{$\begin{array}{c}\text { Velocity }(\mathrm{m} / \mathrm{s}) \\
\text { II }\end{array}$} \\
\hline & $*$ & $\begin{array}{l}\text { bInitial } \\
\text { pattern }\end{array}$ & I & II & \\
\hline 1 & 1063.79 & 1139.40 & 1039.33 & 1035.87 & 7.54 \\
\hline 2 & 1275.66 & 1200.00 & 1300.07 & 1303.53 & 9.49 \\
\hline 3 & 885.75 & 810.09 & 910.16 & 913.62 & 8.23 \\
\hline 4 & 242.41 & 166.74 & 266.81 & 270.27 & 7.93 \\
\hline 5 & 1014.74 & 1000.00 & 990.44 & 987.06 & 8.89 \\
\hline 6 & 992.22 & 1029.23 & 968.09 & 964.97 & 8.69 \\
\hline 7 & 962.41 & 1038.04 & 937.97 & 934.51 & 8.41 \\
\hline 8 & 567.08 & 450.00 & 550.77 & 544.21 & 6.20 \\
\hline 9 & 535.89 & 418.81 & 519.58 & 513.02 & 5.84 \\
\hline 10 & 504.70 & 387.62 & 488.39 & 481.83 & 6.77 \\
\hline 11 & 454.43 & 300.00 & 439.66 & 434.48 & 6.11 \\
\hline 12 & 442.73 & 288.30 & 427.96 & 422.78 & 5.94 \\
\hline 13 & 23.64 & 64.91 & 22.11 & 21.40 & 3.91 \\
\hline 14 & 11.21 & 152.30 & 7.15 & 6.85 & 1.96 \\
\hline 15 & -11.73 & 137.98 & -7.08 & -7.52 & 2.15 \\
\hline 16 & -27.41 & 49.40 & -25.85 & -25.35 & 4.63 \\
\hline 17 & -1.81 & 64.22 & -0.33 & 0.52 & 0.24 \\
\hline 18 & 388.10 & 454.13 & 389.58 & 390.43 & 9.07 \\
\hline 19 & 25.65 & 116.01 & 25.50 & 25.41 & 4.64 \\
\hline 20 & 0.88 & 52.62 & 1.04 & 1.29 & 1.92 \\
\hline 21 & 1.38 & 40.00 & 1.07 & 0.73 & 1.09 \\
\hline 22 & 293.95 & 486.66 & 285.83 & 288.91 & 8.48 \\
\hline 23 & $270-14$ & 500.20 & 260.47 & 262.18 & 6.09 \\
\hline 24 & 38.58 & 75.92 & 37.02 & 35.65 & 4.11 \\
\hline 25 & 151.27 & 100.00 & 153.80 & 147.75 & 5.58 \\
\hline 26 & 2.49 & 50.00 & 2.95 & 2.69 & 1.27 \\
\hline 27 & 398.01 & 576.81 & 390.87 & 386.54 & 6.88 \\
\hline 28 & 589.62 & 769.56 & 608.44 & 608.08 & 8.55 \\
\hline 29 & 521.92 & 749.38 & 541.21 & 540.58 & 7.60 \\
\hline 30 & 354.05 & 625.99 & 378.08 & 376.63 & 8.75 \\
\hline 31 & 144.48 & 100.00 & 139.74 & 140.56 & 5.31 \\
\hline 32 & 19.79 & 48.21 & 18.14 & 18.02 & 5.14 \\
\hline 33 & 77.90 & 5.00 & 74.81 & 75.75 & $8.73^{c}$ \\
\hline 34 & 184.30 & 102.60 & 196.54 & 196.90 & 7.43 \\
\hline 35 & 169.00 & 115.72 & 179.60 & 179.82 & 6.79 \\
\hline 36 & 14.72 & 76.61 & 12.83 & 12.45 & 3.55 \\
\hline 37 & 148.62 & 157.24 & 157.34 & 157.18 & 5.93 \\
\hline 38 & 146.36 & 500.00 & 158.14 & 156.35 & 5.90 \\
\hline 39 & 108.25 & 400.00 & 121.93 & 120.51 & 4.55 \\
\hline 40 & 299.49 & 399.32 & 296.97 & 297.39 & 11.22 \\
\hline 41 & 214.64 & 22.71 & 198.43 & 200.27 & 7.56 \\
\hline 42 & 244.42 & 100.00 & 228.67 & 230.24 & 8.69 \\
\hline 43 & 341.69 & 200.00 & 364.62 & 367.23 & 8.53 \\
\hline
\end{tabular}

*Previous results from 1994.; Results II are recommended ative procedure), 'velocity is above critical value (pipe diameter in branch 33 should be increased; whole calculation have to be repeated)

Values of hydraulics resistances and pressure drops are compared in Table 1 ( $\mathrm{S}_{1}$ for Shifrinson (1937) friction factor, and $S_{2}$ for Renouard (1962) friction factor (Coelho and Pinho, 2007). Previous calculation from 1994. with Shifrinson friction factor (1937) is repeated with initial flow pattern and shown in Table 2 for flows (columns marked as ' $*$ ' and ' $I$ '), and for pressure drops in Table 1 (columns marked as ‘*; eq (20)' and 'I; eq 
(20)'). Final results are gotten after 146 iterations according to original Hardy Cross (1936) method, and only after two iterations even more accurate results according to improved Hardy Cross method. Same calculation is made with Renourad (1962) equation Coelho and Pinho, 2007) for pressure drops (Table 1; column 'II; eq (21)') and for flow (Table 2; column 'II). Initial flow pattern according to first Kirchhoff's law is shown in (Table 2; column 'initial pattern'). Previous results from 1994. are shown also in tables 1 and 2 and they are clearly marked.

In Table 1 and 2 are shown results with more demanded criterions (compared to previous calculation from 1994.) for interrupting of iterative procedure (algebraic sum of pressure drop per contour must be approximately zero). On that way results can be compared.

The flow direction in branches 15, and 16 (and 17 with Shifrinson (1937) friction factor) is opposite to the flow direction shown in Fig. 3.

Inappropriate usage of friction factor is not visible significantly in the results of a flow calculation (Table 2 ), but for pressure calculation, errors are significant (Table 1). Correct results for flows can be done using eq 22 , but calculated pressure drop is even then under expected values (perhaps like in waterworks).

$$
\begin{aligned}
& \Delta_{\mathrm{j}}=\frac{\sum\left\{\mathrm{S}_{1 \mathrm{i}} \cdot \mathrm{Q}_{\mathrm{i}}^{2}\right\}_{\mathrm{j}}}{\sum 2 \cdot\left|\left\{\mathrm{S}_{1 \mathrm{i}} \cdot \mathrm{Q}_{\mathrm{i}}\right\}_{\mathrm{j}}\right|}= \\
& =\frac{\sum_{\mathrm{i}}\left\{\frac{8 \cdot 0.172 \cdot \mathrm{Re}^{-0.18} \cdot \mathrm{L}_{\mathrm{i}} \cdot \mathrm{Q}_{\mathrm{i}}^{2}}{\pi^{2} \cdot \mathrm{D}_{\mathrm{i}}^{5}}\right\}_{\mathrm{j}}}{2 \cdot \sum_{\mathrm{i}}\left|\frac{8 \cdot 0.172 \cdot \mathrm{Re}^{-0.18} \cdot \mathrm{L}_{\mathrm{i}} \cdot \mathrm{Q}_{\mathrm{i}}}{\pi^{2} \cdot \mathrm{D}_{\mathrm{i}}^{5}}\right|_{\mathrm{j}}}
\end{aligned}
$$

Finally, in Fig 4 is shown behavior of calculated pressure drop during iterative procedure in e.g. loop VII of the network shown in Fig 3. Similar conclusion can be done for pressure drops in other loops, and for pressure in each pipes, and also for correction flows $\Delta \mathrm{j}$ in all loops.

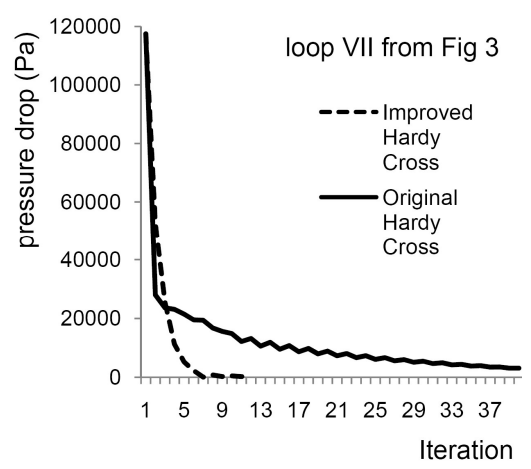

Figure 4. Speed of convergency in iterative procedure original vs. improved Hardy Cross method (example)

\section{Nomenclature}

p-pressure $(\mathrm{Pa})$

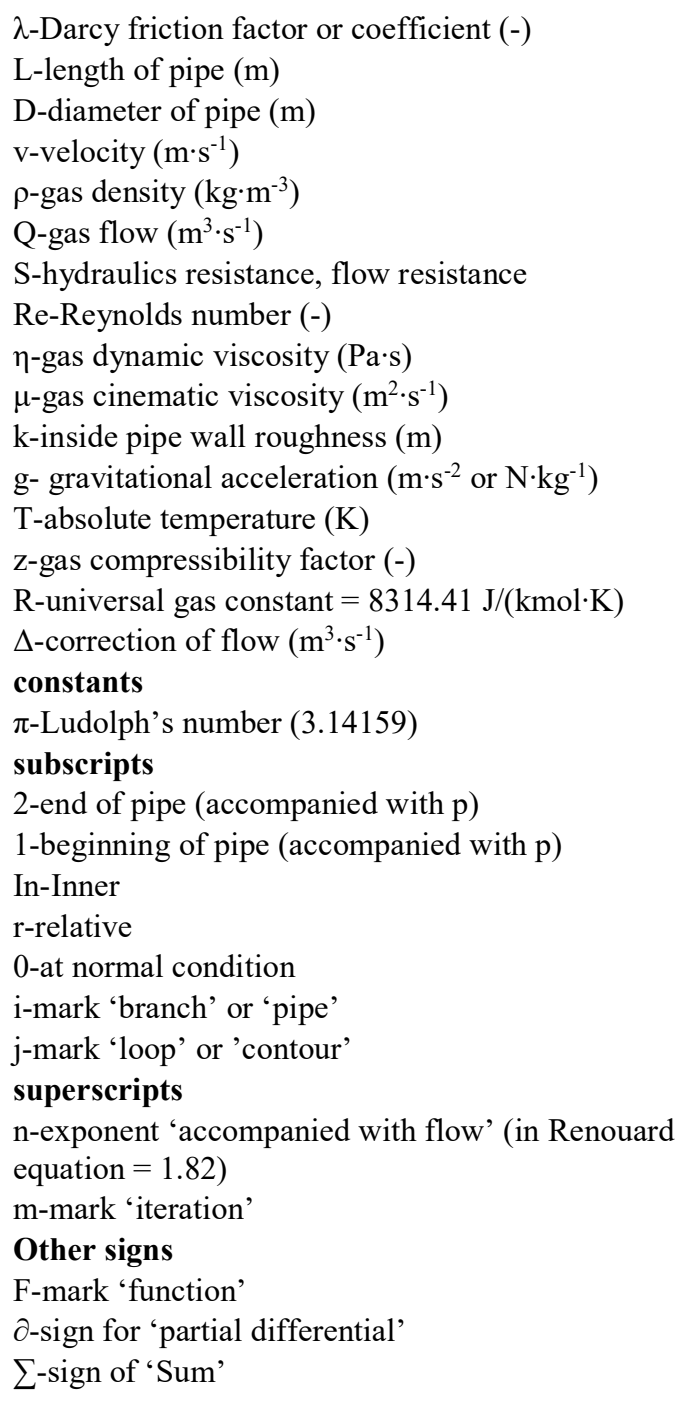

\section{CONCLUSIONS}

Hardy Cross method procedure can give good results when designing a looped gas-pipeline network of composite structure. According to the price and velocity limits, the optimal design can be predicted. But all parameters, e.g. friction factor, relation for calculation of pressure drop in pipes, equation for calculation of gas flow, and similar must be chosen in a very careful way. Today, distributive gas network is usually calculated using Renouard equation for determination of gas flow and pressure drop value. Flow regime in the typical network is partially turbulent. Adoption of inappropriate friction factor or equation can cause significant errors in calculated pressure drops per pipes-in our case from 20 to 130 times (and in pipe 17 with laminar flow regimes up to 1000 times).

According to practical limitations for natural gas pipeline flow and taking into account typical pipe roughness, it is possible to conclude that for pressures below $5 \cdot 10^{5} \mathrm{~Pa}$ and for cooper and polyethylene pipes (usually these types of pipes are smooth), the only available flow regime is the partially turbulent flow and 
in such circumstances the pipe roughness is not required for calculation purposes (Reynolds number is required). However, for steel pipes (Langelandsvik et al., 2008) (usually this type of pipes is not smooth) the existence of the partially or even fully turbulent flow is common and it is not correct to use in the calculations flow equations that ignore the influence of internal pipe roughness (in our case $\min \mathrm{e} / \mathrm{D}=0.000032$, $\max \mathrm{e} / \mathrm{D}=0.000455$, and first minimal roughness in fig 1 is $e / D=1 / 500=0.002$; below values are for smooth pipes and in spite of that the type of pipes even had not been reported in the paper of Manojlović et al., (1994) and investigations of real inner roughness (polyethylene pipes are used in Kragujevac) of the pipeline in Kragujevac has not available to the author of this paper at this time).

In the fact, appropriate solution of problem described here must satisfy three basic requirements $\left(\mathrm{N}^{\circ} 3\right.$ is the basic subject of discussion in this paper):

1. Continuity must be satisfied. That is, the flow into a node of the network must equal the flow out of junction. This must be satisfied for all nodes in each of the iteration.

2. The pressure drop between any two nodes must be the same regardless of the path in the series of pipes taken to get from one junction to the other, and

3. The flow and pressure drop must be consistent with the appropriate velocity-pressure drop equation.

\section{REFERENCES}

Altshul, A.D., Гидравлицескије сопротивљеније, Nedra, Moscow (1982). /in Russian/

Bernuth, von R.D. and T. Wilson, "Friction factors for small diameter plastic pipes," J. Hydraul. Eng. ASCE., 115, 183-192 (1989).

Blasius, H., "Grenzschichten in Flüssigkeiten mit kleiner Reibung," Z. Angew. Math. Phys., 56, 1-37 (1908). /in German/

Chen, N.H., "An explicit equation for friction factor in pipe," Ind. Eng. Chem. Res., 18, 296-297 (1979).

Churchil, S.W., "Friction factor equation spans all fluid flow regimes," Chem. Eng. Prog., 84, 91-92 (1977).

Cross, H., "Analysis of flow in networks of conduits or conductors," Engineering Experimental Station., 286, 3-29 (1936).

Coelho, P.M. and C. Pinho, "Considerations about equations for steady state flow in natural gas pipelines," $J$. of the Brazilian Society of Mechanical Sciences and Engineering., 29, 262-273 (2007).

Colebrook, C.F. and C.M. White, "Experiments with fluid friction in roughened pipes," P. Roy. Soc. A.Math. Phy., 161, 367-381 (1937).

Colebrook, C.F., "Turbulent flow in pipes with particular reference to the transition region between the smooth and rough pipe laws," J. Inst. Civil Engr., 11, 133-156 (1939).
Darcy, H., Recherches Experimentales Relatives au Mouvement de L'Eau dans les Tuyaux, MalletBachelier, Paris (1857). /in French/

Epp, R. and A.G. Fowler, "Efficient code for steady flows in networks," J. Hydraul. Eng.-ASCE., 96, 43-56 (1970).

Kim, S., "Impedance matrix method for transient analysis of complicated pipe networks," J Hydraul Res., 45, 818-828 (2007).

Langelandsvik, L.I., G.J. Kunkel, and A.J. Smits, "Flow in a commercial steel pipe," J. Fluid. Mech., 595, 323-339 (2008).

Manojlović, V., M. Arsenović and V. Pajović, "Optimized design of a gas-distribution pipeline network," Appl. Energ., 48, 217-224 (1994).

Moody, L.F., "Friction factors for pipe flow," J. Appl. Mech.-T. ASME., 66, 671-684 (1944).

Moody, L.F., "An approximate formula for pipe friction factors," J. Appl. Mech.-T. ASME., 69, 1005-1006 (1947).

Nekrasov, B., Hydraulics for aeronautical engineers, Mir publishers, Moscow (1969).

Nikuradse, J., Strömungsgezetze in rauchen Rohren, Verlag, Berlin (1933). /in German/

Obrović, B. and M. Šašić, Hidraulika, Naučna knjiga, Beograd (1990). /in Serbian/

Renouard, P., "Méthode de calcul concernant l'écoulement du gaz en conduits," Travaux, 329, 179-182 (1962). /in French/

Reynolds, O., "An experimental investigation of the circumstances which determine whether the motion of water shall be direct or sinuous and of the law of resistance in parallel channels," Philos. T. R. Soc. A., 174, 935-982 (1883).

Roberson, J.A. and C.T. Crowe, Engineering fluid mechanics, Houghton Mifflin Company, Boston (1985).

Round, G.F., "An explicit approximation for the friction-factor Reynolds number relation for rough and smooth pipes," Can. J. Chem. Eng., 58, 122-123 (1980).

Romeo, E., C. Royo and A. Monzón, "Improved explicit equations for estimation of the friction factor in rough and smooth pipes," Chem. Eng. J., 86, 369374 (2002).

Samani, H.M.V. and S.T. Naeeni, "Optimization of water distribution networks," J Hydraul Res., 34, 623632 (1996).

Sorbu, I. and I. Borza, "Optimal design of water distribution networks," J Hydraul Res., 35, 63-79 (1997).

Shifrinson, B.L., "New Method for District Water System Optimization," Heat and Power, 2, 4-9 (1937).

Swamee, P.K. and A.K. Jain, "Explicit equations for pipe-flow problems," J. Hydraul. Eng.-ASCE., 102, 657-664 (1976). 